Revista de Filología Románica

ISSN: 0212-999X

http://dx.doi.org/10.5209/RFRM.58161

\title{
Cuentos y novelas: Expresión verbal y creatividad narrativa
}

Leonardo Romero Tobar ${ }^{1}$

Recibido: 5 de abril de 2017 / Aceptado: 4 de octubre de 2017

Resumen. Este artículo se detiene en las narraciones de Alonso Zamora Vicente e intenta delimitar la frontera entre los cuentos y las novelas, reflejo de la colectividad presente en el universo narrativo del autor.

Palabras clave: Literatura española; Alonso Zamora Vicente.

\section{[en] Tales and Novels: Verbal expression and narrative creativity}

\begin{abstract}
This article delves into the narrations of Alonso Zamora Vicente and tries to delimit the border between his tales and his novels, a reflection of the collective present in the narrative universe of the author.
\end{abstract}

Keywords: Spanish Literature; Alonso Zamora Vicente.

Sumario: 1. Introducción; 2. La obra narrativa de Alonso Zamora Vicente; 3. Alonso Zamora Vicente, crítico literario; 4.La caracterización de las novelas y cuentos de Alonso Zamora Vicente: Smith y Ramírez, S.A., Mesa, sobremesa y Vegas Bajas; 5. Referencias bibliográficas.

Cómo citar: Romero Tobar, L. (2017). Cuentos y novelas: Expresión verbal y creatividad narrativa, en Revista de Filología Románica 34. Núm. especial, 117-124.

\section{Introducción}

Aunque el Zamora Vicente crítico de relatos había comenzado su andadura en los años 1942 y 1943 (Postigo Aldeamil 1988:551), su creación narrativa específica no se manifestó públicamente hasta el año 1949 durante su estancia en Buenos Aires, cuando Arturo Mallea lo invitó a colaborar en La Nación, donde el filólogo español se estrenó con el evocativo artículo "Compostela lejos" (Zamora Vicente 1949) al que seguirían otros de hechura crítico-literaria o de evocación intimista que darían paso a las invenciones narrativas cuya primera prueba pública en España se puede datar en 1954 con la publicación del relato "Anita" en la revista Ínsula (Zamora Vicente 1954:12). Distintos diarios y revistas fueron publicando sus ficciones bre- 
ves que el propio escritor recogería después en diecinueve libros que van marcando su trayectoria creativa desde la prosa lírica y evocativa hacia la representación emocionada y ferozmente irónica de la sociedad española que él fue conociendo a lo largo de su vida ${ }^{2}$.

\section{La obra narrativa de Alonso Zamora Vicente}

Los comentaristas de la obra narrativa de Zamora Vicente -siguiendo las pautas de Jesús Sánchez Lobato (Sánchez Lobato 1982:22-43) - han establecido una trayectoria creativa en la que cada etapa integra los rasgos característicos de la fase anterior con una pieza representativa y otras que la complementan. Sintetizando, puede decirse que se han determinado cuatro fases en la trayectoria narrativa de Zamora Vicente. Cuatro fases que se inician con su libro Primeras hojas (Zamora Vicente 1955) y los otros que conceden primacía a la evocación personal de lo vivido por el autor en sus años más jóvenes, momento que es seguido por una apertura a la representación de un mundo exterior en el que se impone la visión grotesca de raíz kafkiana, Smith y Ramírez, S. A. (Zamora Vicente 1957) sería la pieza más característica de ese momento. La huella de Kafka en este relato y la de Joyce, Dos Passos o Faulkner en los textos escritos después es manifiesta. Lo extravagante de esta etapa se atenúa en la tercera y más extensa en textos en los que se ha impuesto la visión entre irónica y sentimental de la gente (en el sentido orteguiano de la palabra) que llena espacios públicos y privados; de estos peldaños se llega a un momento de plenitud que ha sido denominado del relato entero y abierto y cuya pieza más representativa es la novela Vegas bajas (Zamora Vicente 1987) en la que se integran características de las colecciones de relatos en cuyo título figura la marca semántica de las palabras habladas: Voces sin rostro (Zamora Vicente 1989), Mentirijillas (Zamora Vicente 1991), Hablan de la feria..., (Zamora Vicente 1995), Historias de viva voz (Zamora Vicente 1995). La última selección aparecida el año 2000 apela en su título Estos pobres diablos (Zamora Vicente 2000) a personajes triviales y errantes como los que habían aparecido en sus otros relatos, incapaces de eludir la tutela del ser maléfico por antonomasia.

También los comentaristas han ido sistematizando las marcas formales y características de contenido presentes en la obra narrativa de Zamora Vicente. Por supuesto que ninguno ha podido ignorar la fuerza expresiva que tiene el léxico en estos textos con el despliegue de sus varias procedencias diatópicas y diastráticas, y la mayoría de los críticos ha pergeñado el modelo narrativo en el que se interpenetran la enunciación del narrador y el habla externa o el fluir de la conciencia de los personajes entretejiendo el discurso directo con el indirecto libre y el monólogo interior ${ }^{3}$. No se han desatendido los homenajes explícitos a autores admirados -Gil Vicente,

2 Exclúyanse de este conjunto los volúmenes recopilatorios en los que el autor se proyecta en la lectura crítica de autores y obras o en las evocaciones de filólogos y escritores a los que había tratado y por los que manifestaba una atracción personal; véase el libro Recuerdos filológicos y literarios (Zamora Vicente 2010) exhumado por Mario Pedrazuela con posterioridad a su muerte.

3 Los recursos gráficos, incluso, que van señalando las variaciones de las voces también han sido subrayados, si bien sería pertinente una sistematización del conjunto de estos recursos que, en mi lectura, corresponden a los entrecomillados, los blancos de página y puntos aparte, la alternancia de tipografía en letra redonda y bastardilla o la composición en dos niveles de la misma página de dos discursos diferenciados. 
Cervantes, Valle Inclán, César Vallejo...- y a formas de la literatura popular como la zarzuela y los romances o a las manifestaciones culturales de consumo general como fueron los pregones y lo son ahora las canciones de moda y las películas.

En el orden de las referencias histórico-culturales, tiene peculiar relieve la reiterada alusión a los trágicos años de la guerra civil con el engrisado autoritarismo que la siguió, además de los ecos de la vida pública española anterior a 1936 y de las modalidades consumistas y tecnológicas que don Alonso pudo conocer en los años de plenitud de su existencia. Todas estas circunstancias son componentes del marco de vida colectiva en el que nuestro autor dibujaba a sus personajes y los conflictos que les aquejaban. Valga un ejemplo ilustrativo de su despierta captación de las transformaciones materiales que se daban en la España de los años setenta del siglo XX en esta cita del cuento "No conviene aparentar" incluido en A traque barraque:

Tú vas a hacer un curso acelerado para manejar la computadora, que al año que viene voy a tener más devengos. Y harás fichas, una por cada sueldo, y las perforarás. Resulta muy distraído. No, de colores diferentes no. No habrá bastantes. Es más práctico hacer agujeritos. Además, el material, la máquina, todo será de la nueva distribuidora-aseguradora que vamos a hacer, y no tendremos que pagar nada (Zamora Vicente 1972:195).

\section{Alonso Zamora Vicente, crítico literario}

Fijarse en los juicios que sobre cuestiones de escritura narrativa ha formulado don Alonso ha sido también otra vía de acceso a la exégesis de su obra. Imprescindible ha sido su comunicación "Yo escribo los domingos", hecha en la Universidad Menéndez y Pelayo, el año 1969, y que constituye una conmovedora confesión y autocrítica:

Toda esta gente que ahora sale por mis narraciones, artículos o lo que sean, que a mí me da igual llamarlos Pepe, son gente. Gente. Son los míos, los que me recuerdan que no estoy solo, y quizás también los que van escoltando el inevitable deslizamiento hacia la más radical soledad, la más numerosamente poblada (Zamora Vicente 1969:284-285).

En esta declaración su autor no precisaba la palabra exacta que correspondía a la determinación genérica de sus escritos de ficción, una cuestión que también ha preocupado a sus comentaristas y que para mí es el punto central de mi propuesta: delimitar la frontera entre novelas y cuentos en el conjunto de este sugestivo cuerpo de textos narrativos. Por supuesto que no se trata de aplicar rótulos convencionales de la tipología retórica como recordaba Cela en su prólogo a Sin levantar cabeza "contar en -literatura- es desnudar la verdad y la mentira para que nadie pueda reconocerlas por su ropaje" (Cela 1977). Compleja cuestión ésta a la que el propio Zamora Vicente volvería en diversas momentos de su obra narrativa, como cuando define Smith y Ramírez, S. A. llamándola "novelita corta" (Zamora Vicente: 1979) o cuan-

4 "Los preceptistas distinguen con muy prolijas razones, no siempre razonables, entre poema en prosa, cuento, relato, narración, novela breve y novela" (Cela 1977:10), catalogación a la que se ha añadido la de estampa y cuadro para emparentar los textos con la tradición costumbrista y la de ficción para señalar el componente inventivo que poseen. 
do, con singular agudeza, explica su teoría del género narrativo en el capítulo de Vegas bajas (Zamora Vicente 1987) en que el joven escritor pueblerino Chucho responde a la pregunta de su amigo Juanjo sobre su proyecto de escribir una novela “¿Cómo la concibes, la novela?” con una extensa explicación de la que recuerdo lo que sigue:

La veo entera, entera y abierta. Una novela donde quepa todo, lo bueno y lo malo, las coyunturas felices y las desgraciadas, con todos los recursos posibles de exposición narrativa... Una novela donde la gente hable, sueñe, duerma, discuta consigo misma (...). En primer lugar, no tendrá un personaje concreto. Ya hemos pasado eso. Los hombres no estamos aislados, no obramos con arreglo a una falsilla interior, sino que somos un conjunto, y de ese con junto hay que hablar (...). Yo no sé por qué, pienso que la novela ha de ser cosa de espíritu bastante maduro, viejo, sí, para entendernos, es decir, con muchas voces y acaeceres dentro (Zamora Vicente 1987:336-342).

\section{La caracterización de las novelas y cuentos de Alonso Zamora Vicente: Smith y Ramírez, S.A, Mesa, sobremesa y Vegas Bajas}

Tan de acuerdo estoy con estos asertos que en mi delimitación entre las novelas y los cuentos de Zamora Vicente, la novela de 1987 -cuando don Alonso contaba setenta años- cumple rigurosamente los supuestos predicados. Delimitaciones estrictamente externas como la impronta editorial o la extensión del relato no son suficientes para la caracterización de unas y otros. La representación narrativa de los enredos humanos que exhiben las novelas no consiste sólo en la implicación de varios personajes en un conflicto con un antes y un después (aunque el pasado se viva también en el recuerdo) sino que, además, sus hilos tienen que enredarse de una forma que modifique la vibración de los individuos e, incluso, de la colectividad. Estos rasgos se manifiestan atenuadamente en tres obras del autor -Un balcón a la plaza (Zamora Vicente 1965), Smith y Ramírez, S. A. (Zamora Vicente 1957) y Mesa, sobremesa (Zamora Vicente 1980) - y con plenitud manifiesta en Vegas bajas (Zamora Vicente 1987).

Smith y Ramírez, S. A. (Zamora Vicente 1957) da título a una recopilación de siete relatos ${ }^{5}$ en los que las técnicas experimentales y la visión absurda de la realidad -desdoblamientos de personalidad, doble plano en el fluir de las concienciascorren parejas con la representación irónica de escenarios cercanos (Madrid) y lejanos (el imaginado lugar americano de Apiguaytay) y con la invasión de la entonces novísima mercadotecnia de los grandes almacenes.

En unos almacenes que llevan el rótulo del relato ocurre la acción de la "novelita" en la que una cuidadora de niños pierde a la criatura de tres años a la que atiende y que será conservada en el departamento de Niños Perdidos, niña que no podrá ser rescatada hasta que contraiga matrimonio a los dieciocho y sea electrocutada en el vuelo nupcial. El absurdo de un universo cuajado de letreros y fórmulas comerciales -por ejemplo, "vuelva usted mañana"- enmarca la comunicación de Ketita y

El libro va dedicado “A M ${ }^{\mathrm{a}}$. J. (Canellada), silente compañía y desvelada. Ahí van siete historietas. Unas tardes de domingo consumiendo la semana, al filo del duro quehacer del oficio (...)" (Zamora Vicente 1957:7). 
de su ama Ana Falk, gracias a las llamadas telefónicas y a las grabaciones televisivas, además del diario que escribe la niña perdida. El relato transmite con eficacia la sensación de agobio que se puede vivir en unos grandes almacenes en los que su último piso es el lugar de depósito de los niños. Además de intertextualidades obvias como la larriana que he recordado, el piso del refugio de la niña, su diario y el nombre de la cuidadora -Ana Falk- creo que remiten al conmovedor Diario de Anne Frank ${ }^{6}$.

Publicada en la colección de Jorge Cela Trulock La novela popular, el relato extenso Un balcón a la plaza (1965), según la clasificación estándar de la trayectoria del autor, estaría inmerso en el fondo poemático de la primera época e incorporaría un soplo de la fase grotesca. La acción transcurre en la acomodada vivienda de una plácida ciudad de provincias (¿Salamanca?) cuyo bullicio social sólo se hace notar a través de su balcón. El tiempo de la acción es sólo de dos horas, de cuatro a seis de la tarde, en las que asisten al café de una amiga otras cuatro señoras burguesas y la empleada doméstica. En este encuentro tendrán también otra presencia dos jóvenes muchachas que practican la escritura: Úrsula, presentándose en la tertulia con su arrobo de literatura misticoide y Mabelita que, a pesar de no comparecer físicamente, sí se hace presente en la tertulia, gracias a la lectura que hace su madre de fragmentos de una novela sentimentalona que la muchacha había escrito. La contraposición fuera/dentro con sus significados de poesía en libertad y opresión de las convenciones se reitera en amplios diálogos, monólogos internos y la voz del narrador que cierra el relato con estas frases:

El reloj da las seis. Todo cerrado, apenas se oyen las campanadas plurales de la calle, amortiguadas. Llega, en cambio, el pregón clamoroso de un ciego en los soportales, una vasta soledad a la intemperie acompañándole (Zamora Vicente 1965:101).

A la soledad, que cierra esta novela corta, Zamora Vicente contrapone la invasión de individuos de toda índole que asisten a la comidade un homenaje tributado a un quidam en la novela Mesa, sobremesa (Zamora Vicente 1980). Su carta-prólogo al editor se extiende acerca del modo de titular los relatos, la identidad de sus personajes y la clase de comunicación que él establece con estos y que, después de haberlos abandonado, "ya solito, yo comprendí que, en realidad he copiado a Cervantes una vez más, ya que esta carta, Sastre amigo, deberá servir como prólogo" (Zamora Vicente 1980:15). La disposición temporal de la novela responde a los sucesivos momentos del banquete: "Aperitivo", "Consomé", "Congelados", "Guarnición para adelgazar" y los postres con los discursos que "Siempre salen del bolsillo interior".

La cháchara vacía de los comensales y el paralelo discurso interior que viven muchos de ellos despliegan la probada capacidad expresiva de Zamora Vicente, transformado también en el narrador del relato del convite. Concluida la jamancia de los invitados los últimos capítulos se titulan muy coloquialmente "Cada mochuelo a su olivo" y "Otra vez la misma cara de la moneda". El valor que posee esta obra como pieza representativa del hacer de su autor ha sido subrayado ampliamente por los comentaristas y sus aportaciones me eximen de insistir sobre sus características (Vilches Vivancos 2003:269-284; Juan Penalva 2003:343-352; Sandru Mehediti 2003:367-376).

6 Cuya primera edición del original fue en el año 1947. 
Es preciso llegar al año 1987 para encontrar la novela indiscutible de nuestro autor, la polifónica y extensa Vegas bajas (Zamora Vicente 1987), con 602 páginas en la que se compendian la muestra coral de recursos expresivos y una estructura narrativa de atractiva complejidad. Se abre la novela con la superchería de un inventado Diccionario Corográfico en el que quedaría registrado el lugar de la acción, San M. de las Vegas Bajas, un lugar que por otras alusiones geográficas y los rasgos paisajísticos propios se podría situar en La Alcarria, escenario del memorable viaje de Cela. El lugar reúne un conjunto de personajes de edad avanzada que vivieron la guerra civil, jóvenes que responden a las incitaciones de la cultura rock e innominados habitantes de las urbanizaciones construidas en el pantano de la localidad. Tal escenario reproduce el esquema de las contraposiciones bimembres, viejo/auténtico y nuevo/inauténtico, a las que nuestro autor está tan apegado. El texto presenta otras supercherías como es el caso del personaje llamado Opropio que remite al nombre de una calle madrileña, San Opropio, santo inexistente y cuyo nombre, según señaló Francisco Serrano Anguita, sería la mala lectura del letrero Paso Propio.

La dimensión temporal de la novela va señalada expresamente en los títulos de las partes que corresponden a las estaciones del año en las que se desarrolla el juego de afectos y antipatías que se profesan las sucesivas generaciones de los pueblerinos, cuya estratificación social también está muy marcada en la oposición de profesionales y propietarios frente a labriegos y emigrantes. Una extensa coda final titulada con el refrán de Correas, "El tiempo todo lo cura y todo lo muda", avanza en diez años la vida de los personajes para recoger a los que han sido claves en el relato y dar noticia de lo que había sucedido a otros muchos que pululaban en el año central. Los personajes van caracterizados, por supuesto, por su habla personal y también, como en las novelas tradicionales, por algún rasgo físico o algún objeto que les pertenece.

De la galería social de personajes, alcanzan relieve muy señalado las dos criadas de un bar de nombre italiano, Justa y Remedios, y el cartero Manolín cuyo monólogo interior cierra la obra. De los pertenecientes a la clase superior expande sus virtudes una vieja dama, doña Margarita, a cuya vivienda concurren los otros miembros de su grupo social y los jóvenes moral e intelectualmente más inquietos: Juanjo y Chucho. El nombre del segundo ya había aparecido en relatos breves como "Chucho el memorioso", un cuento de Sin levantar cabeza ${ }^{7}$ (Zamora Vicente 1977), y para duplicar en Vegas bajas la personalidad del novelista, pues Chucho resulta ser autor de un premio nacional de literatura que se titulaba Sin levantar cabeza y expone sus ideas sobre la novela en términos similares a los que el propio Zamora Vicente ha formulado en otros lugares. La alusión del escritor a su propia persona es una broma más en el esquema de las duplicaciones y relación que unamunianamente él mantenía con sus propios personajes ${ }^{8}$.

Sin duda el calificativo de este personaje debe de ser un homenaje al relato de Jorge Luis Borges "Funes el memorioso" (Borges 1944).

$8 \quad$ “ Usted cree que no es para ponerse triste ver qué lecturas tiene una clase rectora, la del dinero, la banca los funcionarios altos, todos con el riñón bien cubierto, todos con un pasado de lameculos pluscuamperfectos y enciclopédicos! Chismorrería. Nada más que chismorrería, puñeterías y armas al hombro, como dice mi padre que, por lo menos, lee los cuentos de Aldecoa, de Cela o de Zamora Vicentey se siente acompañado" (Zamora Vicente 1987: 123). 
En fin, el coro de voces que edifica esta novela se suma a otros muchos sonidos para trasladar al lector una directa impresión de vida. Es la impresión que recibe el cartero en las dos líneas finales: "Manolín notó que hasta allí llegaba el rumor de la torrentera, le dolió oírle... Cuando llegaban al patio de las madres, cantó un gallo... (Zamora Vicente 1989:602).

\section{Referencias bibliográficas}

Borges, Jorge Luis (1944): Ficciones. Buenos Aires: Sur.

Cela Trulock, Camilo José (1973): "Alonso Zamora Vicente, hijo de Asunción...”. Papeles de son Armadans 109-110:115-124.

Cela Trulock, Camilo José (1977): “Prólogo", in Alonso Zamora Vicente,Sin levantar cabeza, pp. 9-14. Madrid: Magisterio Español.

De Zulueta, Emilia (1989): "Prólogo", in Alonso Zamora Vicente, Voces sin rostro. Madrid: Espasa-Calpe.

García de la Concha, Víctor (1999): "Prólogo", in Alonso Zamora Vicente, Examen de ingreso. Madrid, años veinte. Madrid: Espasa-Calpe.

Juan Penalva, Joaquín (2003): "Empachos, indigestiones y perspectivismo en Mesa, sobremesa", in Carmen Alemany Bay et al (eds.), Con Alonso Zamora Vicente: (Actas del Congreso Internacional "La Lengua, la Academia, lo Popular, los Clásicos, los Contemporáneos... ”), pp. 343-352. San Vicente del Raspeig: Universidad de Alicante.

Pedrazuela Fuentes, Mario (2010): Alonso Zamora Vicente. Vida y filología. San Vicente del Raspeig: Universidad de Alicante.

Postigo Aldeamil, Ma Josefa (1988): "Bibliografía de Alonso Zamora Vicente", in P. Peira et alii (coords.), Homenaje a Alonso Zamora Vicente, vol. I, pp. 549-571. Madrid: Castalia.

Sánchez Lobato, Jesús (1982): Alonso Zamora Vicente. Madrid: Ministerio de Cultura, Dirección General de Promoción del Libro y la Cinematografía, D.L.

Sandru Mehediti, Tudora (2003): "Sobre la traducción de la novela Mesa, Sobremesa de Alonso Zamora Vicente", in Carmen Alemany Bay et al (eds.), Con Alonso Zamora Vicente: (Actas del Congreso Internacional "La Lengua, la Academia, lo Popular, los Clásicos, los Contemporáneos...”), pp. 367-376. San Vicente del Raspeig: Universidad de Alicante.

Vilches Vivancos, Fernando (2003): “Alonso Zamora Vicente a través de sus narraciones y cuentos", in Carmen Alemany Bay et al (eds.), Con Alonso Zamora Vicente: (Actas del Congreso Internacional "La Lengua, la Academia, lo Popular, los Clásicos, los Contemporáneos...”), pp. 269-284. San Vicente del Raspeig: Publicaciones de la Universidad de Alicante.

Zamora Vicente, Alonso (1949): “Compostela lejos". La Nación [06/09/1949]. Buenos Aires.

Zamora Vicente, Alonso (1954): “Anita”. Ínsula 108:12.

Zamora Vicente, Alonso (1955): Primeras hojas. Madrid: Ínsula.

Zamora Vicente, Alonso (1957): Smith y Ramirez, S. A. Valencia: Castalia.

Zamora Vicente, Alonso (1965): Un balcón a la plaza. Madrid: Alfaguara.

Zamora Vicente, Alonso (1969): "Yo escribo los domingos", in Francisco Ynduráin (ed.), Prosa novelesca actual. Segunda reunión 1968, pp. 284-285. Madrid: 
Ministerio de Educación y Ciencia, Dirección General de Enseñanza Superior e Investigación.

Zamora Vicente, Alonso (1972): A traque barraque. Madrid-Barcelona: Alfaguara. Zamora Vicente, Alonso (1975): Desorganización. Madrid: Espasa-Calpe.

Zamora Vicente, Alonso (1976): El mundo puede ser nuestro. Madrid: Ediciones del Centro.

Zamora Vicente, Alonso (1977): Sin levantar cabeza. Madrid: Magisterio Español.

Zamora Vicente, Alonso (1980): "Carta-prólogo del autor", in Alonso Zamora Vicente, Mesa, sobremesa, pp. 6-15. Madrid: Magisterio Español.

Zamora Vicente, Alonso (1980): Mesa, sobremesa. Madrid: Magisterio Español.

Zamora Vicente, Alonso (1982): Tute de difuntos. Santander: La Isla de los Ratones.

Zamora Vicente, Alonso (1983): Estampas de la calle. Madrid: Ediamérica.

Zamora Vicente, Alonso (1984): Suplemento literario, introducción de Leonardo Romero Tobar. Madrid: Espasa-Calpe.

Zamora Vicente, Alonso (1985): Primeras hojas, [2a ; añade cuatro textos]. Madrid: Espasa-Calpe.

Zamora Vicente, Alonso (1986): Smith y Ramírez, S. A. [2ª ; añade prólogo del autor] Barcelona: Círculo de Lectores.

Zamora Vicente, Alonso (1987): Vegas Bajas. Madrid: Espasa-Calpe.

Zamora Vicente, Alonso (1989): Voces sin rostro. Madrid: Espasa-Calpe.

Zamora Vicente, Alonso (1991): El mundo puede ser nuestro [2 $2^{\mathrm{a}}$ ed., añade prólogo de autor] Barcelona: Círculo de Lectores.

Zamora Vicente, Alonso (1991): Mentirijillas. Albacete: Barcarola Narrativa.

Zamora Vicente, Alonso (1991): Examen de ingreso. Madrid años veinte. Madrid: Espasa-Calpe.

Zamora Vicente, Alonso (1995): Hablan de la feria.... Barcelona: Círculo de Lectores.

Zamora Vicente, Alonso (1995): Historias de viva voz [Reedita 16 textos publicados en Mentirijillas]. Madrid: Alianza.

Zamora Vicente, Alonso (1998): Narraciones, J. Sánchez Lobato (ed.), Madrid: Castalia.

Zamora Vicente, Alonso (1998): Cuentos con gusano dentro. Palma de Mallorca: Bitzoc.

Zamora Vicente, Alonso (1998): "Buscar un título a un libro", in Alonso Zamora Vicente, Cuentos con gusano dentro. Palma de Mallorca: Bitzoc.

Zamora Vicente, Alonso (1999): ¡Estos pobres diablos! Madrid: Biblioteca Antonio de Nebrija.

Zamora Vicente, Alonso (2003): Mesa, sobremesa [2 ed., añade "Advertencia a esta edición"] Barcelona: Círculo de Lectores.

Zamora Vicente, Alonso (2010): Recuerdos filológicos y literarios, edición de Mario Pedrazuela Fuentes. Cáceres: Universidad de Extremadura. 